Prosiding Seminar Nasional Teknologi Informasi dan Kedirgantaraan : Transformasi Teknologi untuk Mendukung Ketahanan Nasional, Yogyakarta, 13 Desember 2018

SENATIK 2018, Vol. IV, ISBN 978-602-52742-0-6

DOI: http://dx.doi.org/10.28989/senatik.v4i0.250

\title{
PROJECT OPTIMIZATION OF WEB-BASED 3D ANIMATION BUS ROUTE TRANS JOGJA USING CPM Nurcahyani Dewi Retnowati
}

Program Studi Informatika

Sekolah Tinggi Teknologi Adisutjipto

Jl. Janti, Blok-R, Lanud Adisucipto Yogyakarta

Email : nurcahyanidr@stta.ac.id

\begin{abstract}
The making of informative media in the form of three-dimensional animation on Trans Jogja bus routes really requires good project planning so that the process becomes more effective and efficient. In planning a project, it is necessary to consider the time, cost and scope of a project. Project optimization is done by using the Critical Path Method (CPM) method, which is a technique of analyzing network activity activities or project activities that predict total duration. Project optimization planning through the stages starting from the creation of the Work Breakdown Structure, barchart diagrams with Gantt Chart software, critical path calculations, and the final stages with CPM to determine the fastest time possible for the project to be completed. The results of the WBS are obtained by predecessor of each activity and its duration, the calculation of the critical path is 29 days with path $a-b$ $c-d-e-f-g-h-I-j-l-m-n-o$, and from the CPM calculation the total float is 0 so the project can be completed on time
\end{abstract}

Keywords: Work Breakdown Structure, critical path, predecessor, early start, latest finish

\section{Abstrak}

Pembuatan media informatif yang berbentuk animasi tiga dimensi pada rute bus Trans Jogja sangat memerlukan adanya perencanaan proyek yang baik agar prosesnya menjadi lebih efektif dan efisien. Dalam perencanaan suatu proyek perlu dipertimbangkan time, cost dan scope dari suatu proyek. Optimasi proyek dilakukan dengan menggunakan metode Critical Path Method (CPM) yang merupakan suatu teknik menganalisis jaringan kegiatan atau aktivitas aktivitas proyek yang memprediksi durasi total. Perencanaan optimasi proyek melalui tahapan mulai dari pembuatan Work Breakdown Structure, diagram barchart dengan software Gantt Chart, perhitungan jalur kritis, dan tahapan terakhir dengan CPM untuk menentukan waktu tercepat yang mungkin agar proyek dapat diselesaikan. Hasil dari WBS didapat predecessor masing-masing kegiatan dan durasinya, perhitungan jalur kritisnya sebanyak 29 hari dengan jalur a-b-c-d-e-f-g-h-I-j-k-l-m-n-o, dan dari perhitungan CPM dihasilkan total float adalah 0 sehingga proyek dapat diselesaikan tepat waktu

Kata Kunci : Work Breakdown Structure, jalur kritis, predecessor, early start, latest finish

\section{Pendahuluan}

Salah satu hal yang mendukung para wisatawan dalam menggunakan bus Trans Jogja adalah peta rute jalur bus. Penggunaan bus Trans Jogja dengan tujuan untuk mengurangi kemacetan lalu lintas [1]. Trans Jogja memiliki beberapa rute bus yang melayani penggunanya di kota Yogyakarta dan sekitarnya, rute yang ada meliputi trayek 1A, 1B, 2A, 
2B, 3A, 3B, 4A, 4B, 5A, 5B, 6A, 6B, 7, 8, 9, 10, dan 11. Total jumlahnya ada 129 armada bus [2].

Peta yang ada di Trans Jogja selain yang ada di setiap shelter juga ada di dalam website Trans Jogja, namun masih dalam bentuk peta konvensional dengan jalur trayek tumpang tindih [3]. Untuk mengatasi kendala tersebut, perlu dibuat suatu media yang dapat memberikan informasi rute setiap trayek jalur bus Trans Jogja. Media tersebut berupa animasi tiga dimensi berbasis web yang dapat lebih informatif. Penyajian yang informatif perpaduan antara teks, gambar, video, suara, dan animasi [4], sehingga menjadi lebih menarik dan dapat memudahkan para wisatawan memahami rute jalur bus trans Jogja.

Oleh karena itu, sangat dibutuhkan suatu perencanaan dalam pembuatan animasi tiga dimensi rute jalur bus Trans Jogja. Perencanaan tersebut meliputi tahapan pembuatan, penjadwalan pembuatan, spesifikasi hardware dan software yang dapat digunakan dalam pembuatan aplikasi, dan analisis kebutuhan sehingga dapat menjadi lebih efektif dan efisien.Tujuan perencanaan tersebut agar dapat membantu pihak Trans Jogja dalam penjadwalan proyek yang harus disiapkan secara sistematis dengan menggunakan sumber daya secara efektif dan efisien sehingga tujuan proyek dapat tercapai secara optimal [5]. Keberhasilan atau kegagalan proyek dapat disebabkan oleh perencanaan yang tidak maksimal dan pengendalian yang tidak efektif, sehingga proyek aktivitas menjadi tidak efisien [6].

\section{Metodologi Penelitian}

Metodologi penelitian yang dilakukan dengan melakukan penentuan spesifikasi hardware dan software yang akan digunakan dalam pembuatan perencanaan proyek, pembuatan tahapan optimasi proyek, pembuatan Work Breakdown Structure (WBS), penentuan predecessor atau ketergantungan antar kegiatan, penentuan jalur kritis, pembuatan diagram Program Evaluation and Review Technique (PERT), pembuatan barchart, perhitungan optimasi proyek dengan menggunakan Critical Path Method (CPM) atau Network Planning.

Gambaran yang lebih detail tentang kegiatan atau pekerjaan yang dilakukan dalam proyek, dapat membagi total pekerjaan menjadi unit-unit yang dapat dikelola dengan menggunakan Work Breakdown Structure (WBS). Tujuan dari pembuatan WBS adalah untuk mengorganisasikan proyek menjadi berbagai level pelaporan yang ringkas [7]. Pembuatan barchart dengan menggunakan software Gantt Chart. Barchart merupakan diagram batang yang sederhana dapat menunjukkan informasi rencana jadwal proyek beserta durasinya, lalu dibandingkan dengan proses aktual sehingga diketahui apakah proyek terlambat atau tidak [8]. Diagram barchart sederhana dapat dilihat pada Gambar 1 dan detail diagram barchart dapat dilihat pada Gambar 2.

\begin{tabular}{|c|c|c|c|c|c|c|c|c|c|}
\hline \multirow{2}{*}{ Task Name } & \multicolumn{3}{|c|}{\begin{tabular}{|l|l}
12009 \\
\end{tabular}} & \multicolumn{3}{|c|}{$Q 22009$} & \multicolumn{3}{|c|}{032009} \\
\hline & Dec '08 & $\operatorname{Jan} 109$ & Feb '09 & Mar '09 & Apr '09 & May '09 & Jun '09 & Jul '09 & Aug \\
\hline Planning & & யIIIII & ZIITIS: & & & & & & \\
\hline Research & & & ШTITIT: & $\mathbb{Z 1 Z}$ & & & & & \\
\hline Design & & & & Шாயா: & & & & & \\
\hline Implementation & & & & & पITITIII & IIIITIS: & & & \\
\hline Follow up & & & & & & & $\mathbb{Z}$ & $\mathbb{Z}$ & \\
\hline
\end{tabular}

Gambar 1. Gantt Chart Sederhana

(Sumber: https://www.gantt.com/ [9]) 


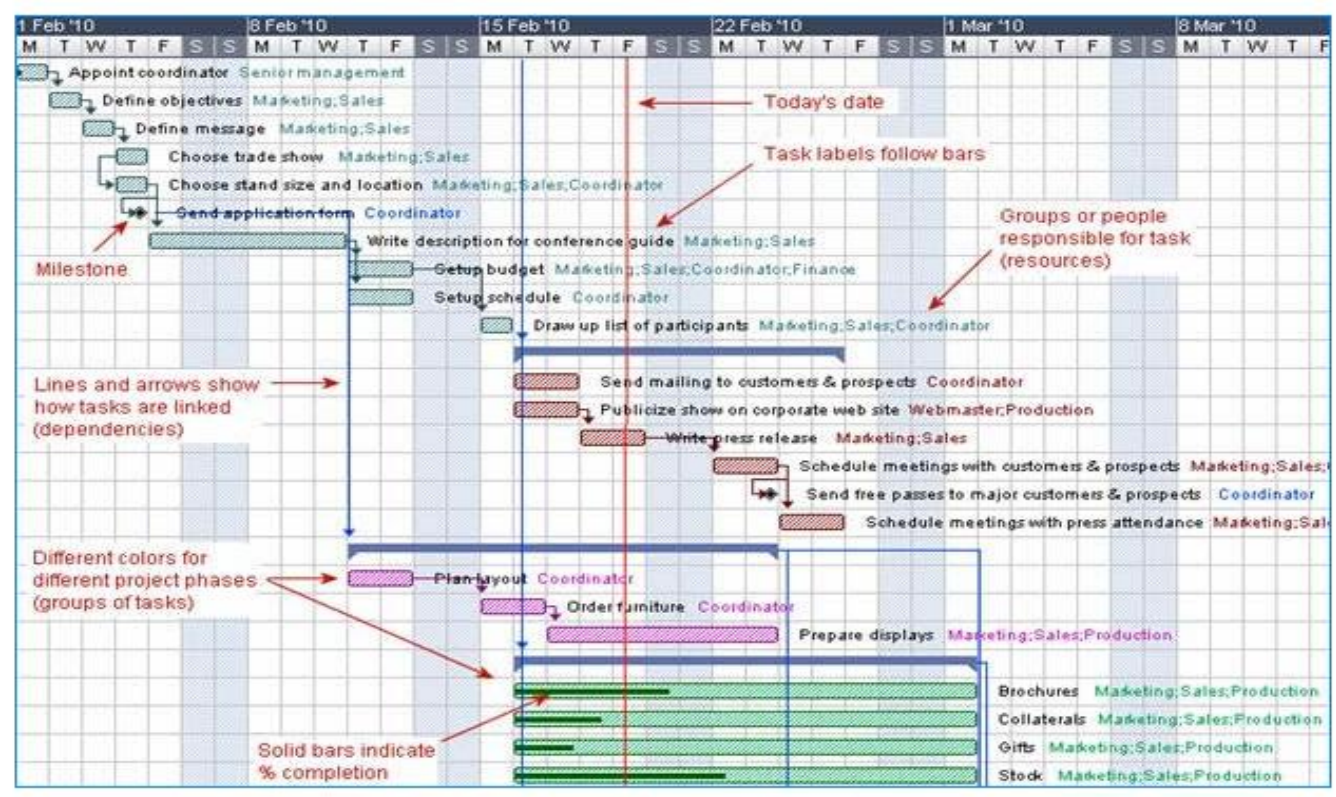

Gambar 2. Bagian Dari Gantt Chart

(Sumber: https://www.gantt.com/ [9])

Network planning yang digunakan adalah metode CPM, sebagai jaringan kerja berbagai kegiatan dapat menunjukkan kegiatan-kegiatan kritis yang membutuhkan pengawasan ketat agar pelaksanaannya tidak keterlambatan. Format Network Planning juga digunakan untuk mengetahui kegiatan-kegiatan yang longgar waktu penyelesaiannya berdasarkan total float-nya, sehingga kesemua itu digunakan untuk memperbaiki jadwal dan agar alokasi sumber dayanya menjadi lebih efektif serta efisien [8].

\section{Perencanaan Dan Analisa}

Work Breakdown Structure pada proyek ini meliputi 5 tahapan yang terbagi lagi menjadi sub-sub tahapan. Tahapan yang pertama adalah analisis dan desain sistem (meliputi menganalisis sistem trayek, halte dan rute bus Trans Jogja dengan pengambilan data dan wawancara dengan petugas yang ada di halte, penentuan hardware dan software yang dapat digunakan dalam pembuatan media informasi, pembuatan flowchart, pembuatan context diagram, diagram alir data, kamus data, process spesification, entity relation database, dan dokumentasi analisis dan desain sistem).

Tahapan yang kedua adalah desain aplikasi yang hanya terdiri dari dari satu kegiatan proyek, yaitu pembuatan desain tampilan user interface.

Tahapan yang ketiga adalah desain animasi yang terdiri dari 3 kegiatan proyek, yaitu desain objek dua dimensi, desain objek tiga dimensi, dan desain animasi. Tahapan yang keempat adalah programming, dan tahapan yang kelima adalah testing. Tabel Work Breakdown Structure dapat dilihat pada Tabel 1.

Pada pembuatan tabel juga dibuat hubungan ketergantungan antar tugas atau kegiatan (Predecessor). hubungan antar tugas atau kegiatan terbagi menjadi 4 macam, yaitu selesai ke mula (FS), mulai ke mulai (SS), selesai ke selesai (FF), dan mulai ke selesai (SF) [10].

Pada tabel 1 predecessornya masuk kategori selesai ke mulai (FS) karena tugas selanjutnya bisa dimulai jika tugas sebelumnya telah selesai dikerjakan. Durasi yang tertulis pada masing-masing kegiatan. Durasi atau kurun waktu menunjukkan lamanya waktu yang dibutuhkan dalam melakukan suatu kegiatan [8]. 
Tabel 1. Work Breakdown Structure Optimasi Proyek

\begin{tabular}{|c|l|c|c|}
\hline No. & \multicolumn{1}{|l|}{ Kegiatan } & Predecessor & Durasi \\
\hline $\mathrm{a}$ & $\begin{array}{l}\text { Menganalisis sistem trayek, halte, dan } \\
\text { rute bus }\end{array}$ & - & 3 hari \\
\hline $\mathrm{b}$ & $\begin{array}{l}\text { Penentuan Hardware dan Software } \\
\text { yang akan digunakan dalam } \\
\text { pembuatan media informasi }\end{array}$ & $\mathrm{a}$ & 1 hari \\
\hline $\mathrm{c}$ & Pembuatan flowchart & $\mathrm{b}$ & 1 hari \\
\hline $\mathrm{d}$ & Pembuatan context diagram & $\mathrm{c}$ & 1 hari \\
\hline $\mathrm{e}$ & Pembuatan diagram alir data & $\mathrm{d}$ & 1 hari \\
\hline $\mathrm{f}$ & Pembuatan kamus data & $\mathrm{e}$ & 1 hari \\
\hline $\mathrm{g}$ & Pembuatan process spesification & $\mathrm{g}$ & 1 hari \\
\hline $\mathrm{h}$ & Pembuatan entity relation database & 2 hari \\
\hline $\mathrm{i}$ & $\begin{array}{l}\text { Dokumentasi analisis dan desain } \\
\text { sistem }\end{array}$ & $\mathrm{h}$ & 1 hari \\
\hline $\mathrm{j}$ & $\begin{array}{l}\text { Membuat desain tampilan user } \\
\text { interface }\end{array}$ & $\mathrm{i}$ & 2 hari \\
\hline $\mathrm{k}$ & Membuat desain objek dua dimensi & $\mathrm{j}$ & 3 hari \\
\hline $\mathrm{l}$. & Membuat desain objek tiga dimensi & $\mathrm{k}$ & 2 hari \\
\hline $\mathrm{m}$. & Membuat animasi & $\mathrm{l}$ & 7 harii \\
\hline $\mathrm{n}$. & Programming & $\mathrm{m}$ & 3 hari \\
\hline o. & Testing & & \\
\hline
\end{tabular}

\section{Hasil dan Pembahasan}

Dilihat dari tabel Work Breakdown Structure (Tabel 1) dapat dianalisis jalur kritis suatu proyek. Jalur kritis dari setiap proyek merupakan jalur terpanjang dalam jaringan. Setiap tugas di jalur kritis yang lepas dari jadwal aslinya akan memperpanjang seluruh jadwal proyek [7]. Dari tabel 1 jika dilihat dari durasi setiap kegiatan, maka jumlah jalur kritisnya sebanyak 29 hari dengan jalur a-b-c-d-e-f-g-h-I-j-k-l-m-n-o.

Pada pembuatan barchart yang menggunakan software Gantt Chart, penentuan kalender kerja menggunakan task calendar. Task calendar tersebut digunakan untuk keperluan proyek yang dijalankan pada malam hari atau akhir pekan (pada project calendar dinyatakan libur) [11]. Setting task calendar, hari sabtu dan hari minggu dianggap sebagai hari libur sehingga tidak terhitung sebagai hari kerja, namun mempengaruhi jalur kritis suatu proyek. Gambar barchart optimasi proyek dapat dilihat pada Gambar 3. 


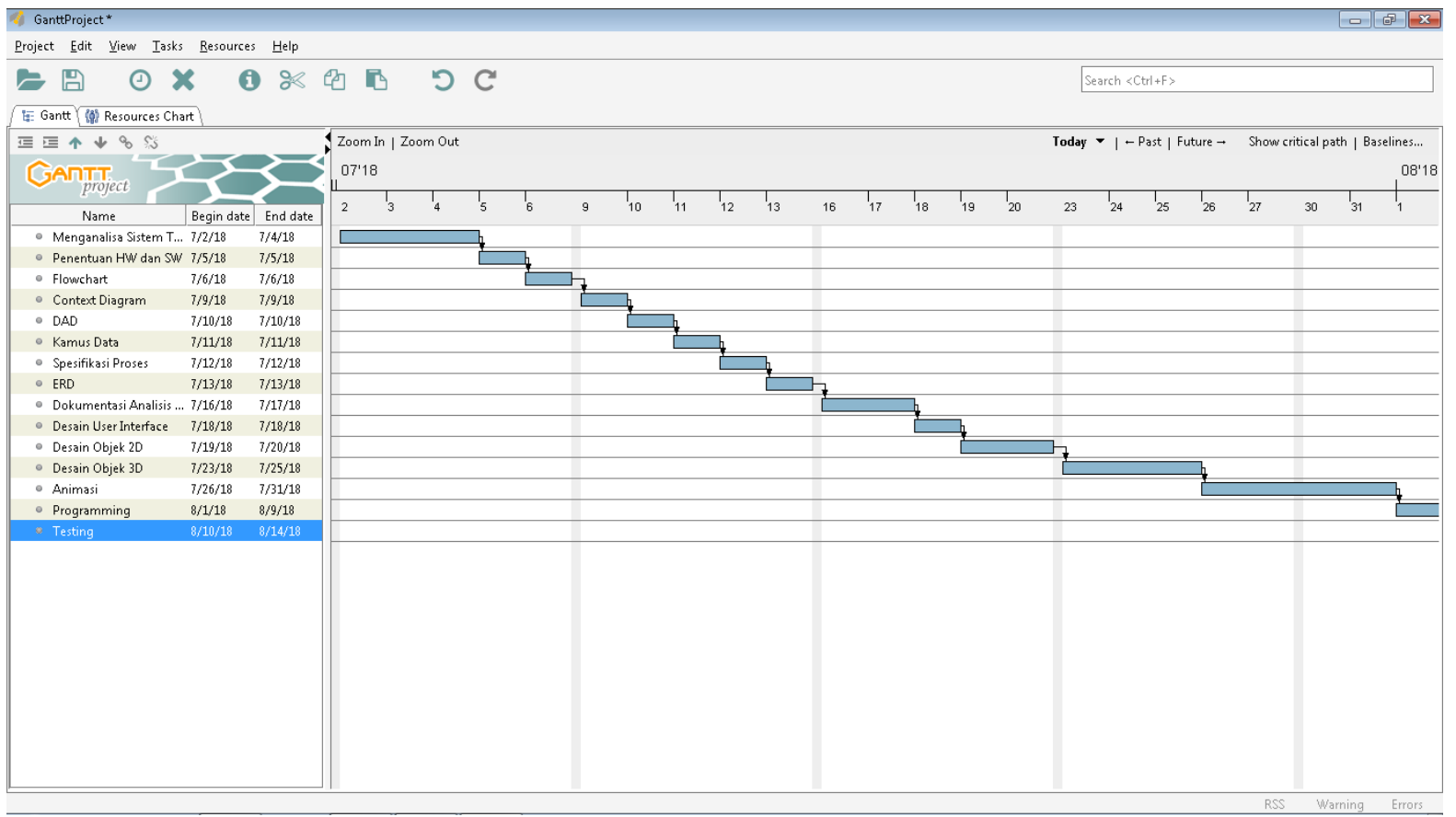

Gambar 3. Barchart Optimasi Proyek yang Dilakukan

Hasil dari diagram Program Evaluation and Review Technique (PERT), dengan masih menggunakan software Gantt Chart, dapat dilihat pada Gambar 4. pada setiap masing-masing kolom kegiatan terdapat keterangan durasi atau kurun waktu kegiatan, tanggal mulai dan tanggal selesai kegiatan.

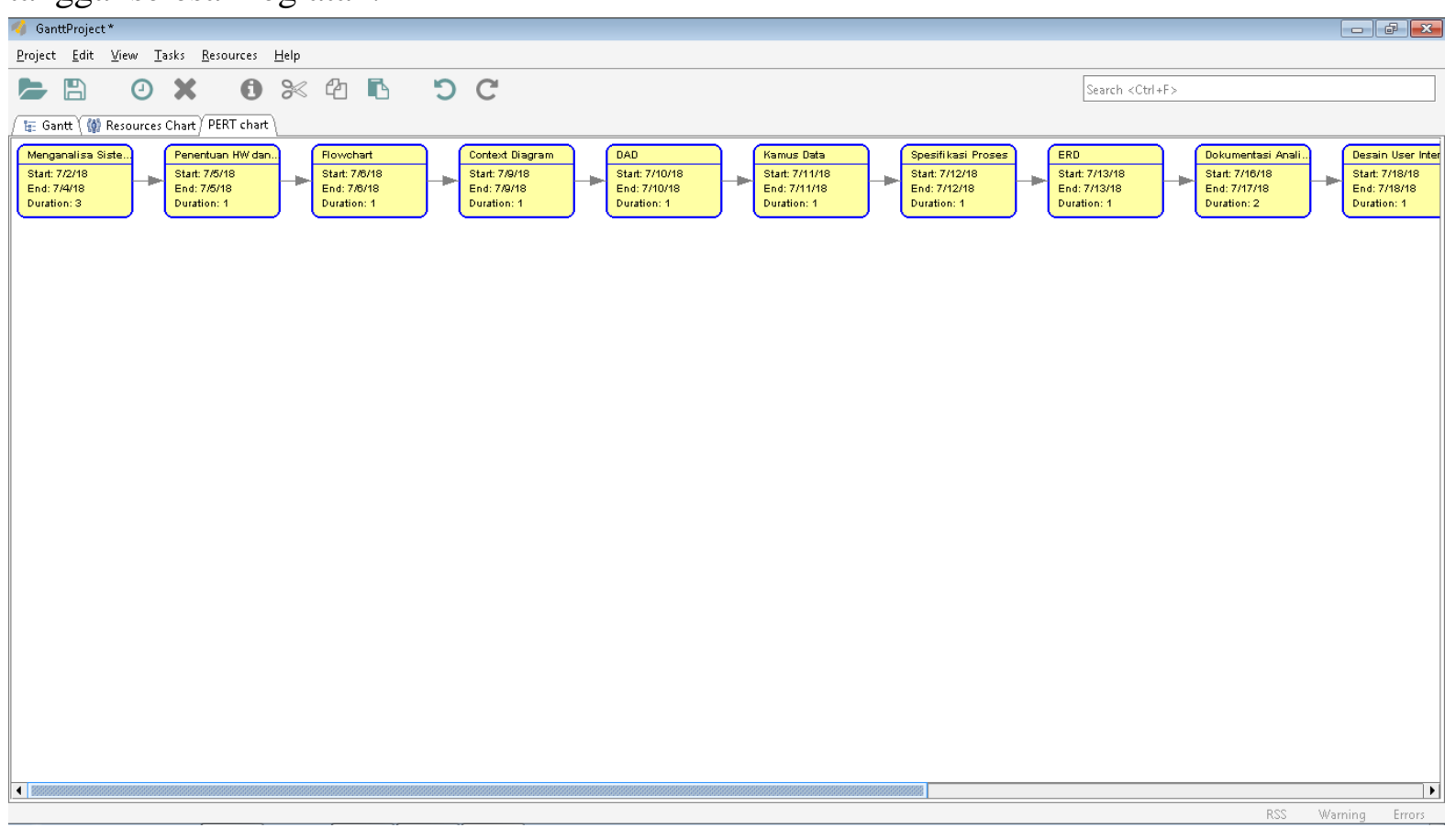

Gambar 4. Diagram PERT Optimasi Proyek

Sedangkan diagram PERT yang menggunakan node-node, dapat dilihat pada Gambar 5. 


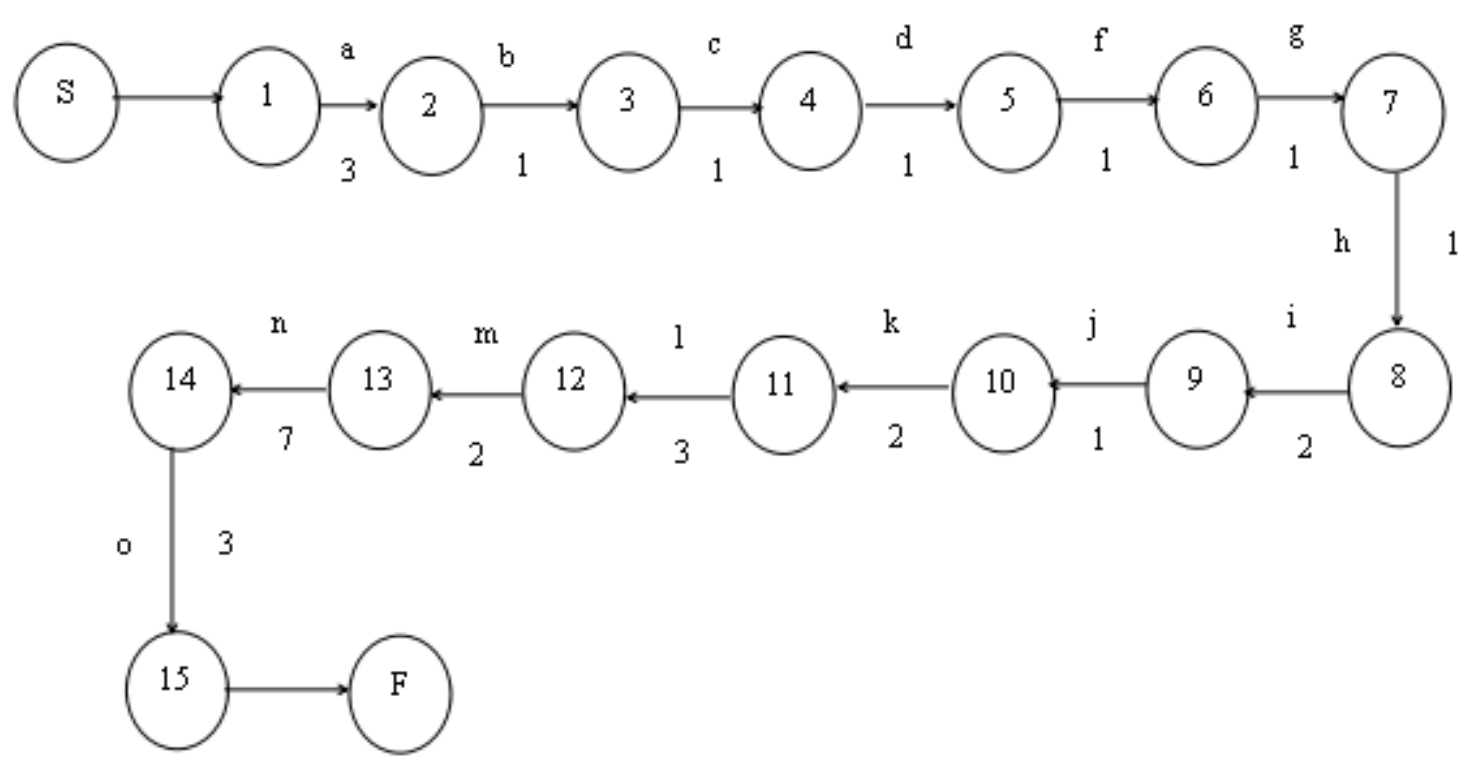

Gambar 5. Diagram PERT yang Menggunakan Node

Diagram PERT selalu dimulai dari node yang disebut dengan node awal. Dari node awal tersebut ditarik garis anak panah untuk merepresentasikan setiap tugas. Pada ujung anak panah, node tambahan dibuat. Kemudian, dari node tambahan ini, tugas yang tergantung dikaitkan sampai semua tugas telah saling berhubungan satu sama lain. Tugas terakhir kemudian dihubungkan dengan node akhir atau node finish. Tipe susunan grafis ini disebut dengan aktivitas anak panah karena aktivitas berlangsung di garis anak panah yang menghubungkan node-node [7].

Pada Gambar 5, digambarkan bahwa node awal adalah a, atau kegiatan menganalisis sistem trayek, halte, dan rute bus. Kegiatan b (penentuan hardware dan software) akan dapat dimulai jika kegiatan a telah selesai dilakukan, sehingga hubungan dua kegiatan tersebut (predecessor) selesai ke mulai (finish to start) dan dihubungkan dengan adanya anak panah antar node a dan node b. begitu pula dengan node-node lain selanjutnya yang saling terhubung dengan node sebelumnya hingga node paling akhir (node finish).

Perhitungan dengan menggunakan CPM didapatkan hasil seperti pada Tabel 2.

Tabel 2. Perhitungan CPM

\begin{tabular}{|c|c|c|c|c|c|}
\hline $\begin{array}{c}\text { Kegiatan } \\
\text { (Durasi) }\end{array}$ & ES & EF & LS & LF & TF \\
\hline $\mathrm{a}(3)$ & $2 / 7$ & $4 / 7$ & $2 / 7$ & $4 / 7$ & 0 \\
\hline $\mathrm{b}(1)$ & $5 / 7$ & $5 / 7$ & $5 / 7$ & $5 / 7$ & 0 \\
\hline $\mathrm{c}(1)$ & $6 / 7$ & $6 / 7$ & $6 / 7$ & $6 / 7$ & 0 \\
\hline $\mathrm{d}(1)$ & $9 / 7$ & $9 / 7$ & $9 / 7$ & $9 / 7$ & 0 \\
\hline $\mathrm{e}(1)$ & $10 / 7$ & $10 / 7$ & $10 / 7$ & $10 / 7$ & 0 \\
\hline $\mathrm{f}(1)$ & $11 / 7$ & $11 / 7$ & $11 / 7$ & $11 / 7$ & 0 \\
\hline $\mathrm{g}(1)$ & $12 / 7$ & $12 / 7$ & $12 / 7$ & $12 / 7$ & 0 \\
\hline $\mathrm{h}(1)$ & $13 / 7$ & $13 / 7$ & $13 / 7$ & $13 / 7$ & 0 \\
\hline $\mathrm{i}(2)$ & $16 / 7$ & $18 / 7$ & $16 / 7$ & $18 / 7$ & 0 \\
\hline $\mathrm{j}(1)$ & $19 / 7$ & $19 / 7$ & $19 / 7$ & $19 / 7$ & 0 \\
\hline $\mathrm{k}(2)$ & $20 / 7$ & $23 / 7$ & $20 / 7$ & $23 / 7$ & 0 \\
\hline $\mathrm{l}(3)$ & $24 / 7$ & $26 / 7$ & $24 / 7$ & $26 / 7$ & 0 \\
\hline
\end{tabular}




\begin{tabular}{|c|c|c|c|c|c|}
\hline $\mathrm{m}(2)$ & $27 / 7$ & $30 / 7$ & $27 / 7$ & $30 / 7$ & 0 \\
\hline $\mathrm{n}(7)$ & $31 / 7$ & $8 / 8$ & $31 / 7$ & $8 / 8$ & 0 \\
\hline $\mathrm{o}(3)$ & $9 / 8$ & $13 / 8$ & $9 / 8$ & $13 / 8$ & 0 \\
\hline
\end{tabular}

Pada kegiatan $\mathrm{n}$ dan o (tabel 2) durasi yang panjang dan adanya hari libur maka waktu selesainya menjadi lebih lama. Total waktu pengerjaan proyek adalah sebanyak 43 hari dengan total kurun waktu atau durasi kerja sebanyak 29 hari. Total float atau lamanya suatu tugas atau kegiatan dapat mundur atau menunda seluruh proyek yang didapat dari perhitungan pada tabel 2 adalah 0 , sehingga proyek akan selesai tepat waktu.

\section{Kesimpulan}

Kesimpulan dari hasil penelitian ini adalah:

1. Optimasi proyek dengan menggunakan tabel WBS dan penentuan predecessor dan barchart dihasilkan hubungan antar kegiatan masuk kategori Finish To Start

2. Dengan perhitungan CPM, didapatkan bahwa total waktu pengerjaan proyek sebanyak 43 hari dengan total kurun waktu atau durasi kerja sebanyak 29 hari.

3. Total float sebanyak 0 sehingga proyek yang dikerjakan akan selesai tepat waktu

\section{Ucapan Terimakasih}

Sekolah Tinggi Teknologi Adisutjipto yang telah membiayai penelitian ini melalui Dana Penelitian Internal STTA tahun anggaran 2017/2018

\section{Daftar Pustaka}

[1] Hormansyah, D. S., Sugiarto, V., \& Amalia, E. L. (2016). Penggunaan Vissim Model Pada Jalur Lalu Lintas Empat Ruas. JURNAL TEKNOLOGI INFORMASI: Teori, Konsep, dan Implementasi, 7(1).

[2] Dinas Perhubungan Daerah Istimewa Yogyakarta, Data Trans Jogja. Online: http://dishub.jogjaprov.go.id/trans-jogja. Diakses 10 September 2018.

[3] Retnowati, N. D. (2017, December). Animasi 3D Rute Jalur Bus Trans Jogja Trayek 1A Dan 3A Berbasis Android. In Conference SENATIK STT Adisutjipto Yogyakarta (Vol. 3, pp. 64-71).

[4] Chang, M., Liliana, L., \& Rostianingsih, S. (2015). Implementasi Animasi Pada Multimedia Interaktif. Jurnal Infra, 3(2), pp-32.

[5] Arifudin, R. (2012). Optimasi penjadwalan proyek dengan penyeimbangan biaya menggunakan kombinasi CPM dan algoritma genetika. Jurnal Masyarakat Informatika, 2(4), 1-14.

[6] Dannyanti, E., \& SUDARYANTO, B. (2011). Optimalisasi Pelaksanaan Proyek dengan Metode Pert dan CPM (Studi Kasus Twin Tower Building Pasca Sarjana Undip) (Doctoral dissertation, UNIVERSITAS DIPONEGORO)

[7] Mingus, Nancy. (2006). Alpha Teach Yourself: Project Management dalam 24 Jam. Jakarta. Prenada

[8] Husen, Abrar. (2011). Manajemen Proyek. Yogyakarta. CV Andi Offset.

[9] Anonim. (2018). What Is Gantt Chart?. Online: https://www.gantt.com/. Diakses 15 Oktober 2018.

[10] Dimyati, Hamdan, Kadar Nurjaman. (2014). Manajemen Proyek. Bandung. CV Pustaka Setia.

[11] Heryanto, Imam, Totok Triwibowo. (2016). Manajemen Proyek Berbasis Teknologi Informasi. Revisi Kedua. Bandung. Penerbit INFORMATIKA. 